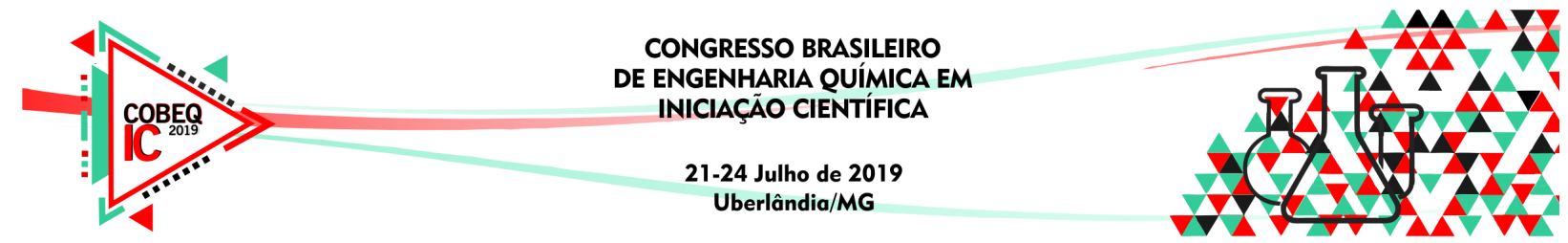

\title{
DETERMINAÇÃO DA BIODEGRADABILIDADE DE TENSOATIVO ANIÔNICO PRESENTE EM DETERGENTE LAVA-ROUPAS LÍQUIDO PRODUZIDO NA REGIÃO METROPOLITANA DE BELO HORIZONTE
}

\author{
C. L. CAETANO ${ }^{1}$, G. F. M. NUNES ${ }^{1}$ e M. L. A. VIEIRA ${ }^{1}$ \\ ${ }^{1}$ Centro Federal de Educação Tecnológica de Minas Gerais (CEFET/MG), \\ Departamento de Química \\ E-mails para contato: carolinalandes@gmail.com; giselenunes@ cefetmg.br; \\ mariana@cefetmg.br
}

\begin{abstract}
RESUMO - Com base na tendência de substituição do detergente lava-roupas em pó, até então, principal produto ao qual se destinavam os tensoativos aniônicos produzidos no Brasil, neste trabalho foi estudada a biodegradabilidade desses surfactantes presentes em amostra comercial de detergente lava-roupas líquido produzido na região metropolitana de Belo Horizonte. Para este estudo, o tensoativo extraído foi colocado em meio reacional contendo microrganismos provenientes de solo de jardim. Em dias pré-determinados analisou-se a concentração desse surfactante no meio, de acordo com o método do azul de metileno determinado pela Agência Nacional de Vigilância Sanitária (ANVISA). Os resultados mostraram que a amostra comercial estudada apresenta elevado teor de matéria ativa aniônica podendo ser considerado um detergente concentrado. Além disso o tensoativo presente na amostra de detergente lava-roupas testada é biodegradável, tendo em vista que sua porcentagem de biodegradabilidade foi superior a $90 \%$ já no $9^{\circ}$ dia de ensaio, ou seja, em tempo inferior ao previsto pela legislação brasileira (até 14 dias) para alcançar este valor.
\end{abstract}

\section{INTRODUÇÃO}

A crescente utilização de detergentes e o avanço da preocupação da população com relação às questões ambientais tem estabelecido um desafio para o setor industrial de produtos de limpeza, mobilizando fabricantes, agências reguladoras e consumidores. (Gonçalves, 2009). Neste setor, os artigos produzidos para cuidados com as roupas são os que mais se destacam (H\&C, 2009). Segundo estudo do BNDES, realizado em 2014, no Brasil, a maior parte dos tensoativos aniônicos era utilizada em detergentes em pó para lavagem de roupas, correspondendo a $59 \%$ do volume de produtos aniônicos empregados no país (BNDES, 2014).

Entretanto, em países como Estados Unidos, Itália e Espanha, a tendência é o segmento de líquidos, que em 2009 já correspondia a $77 \%, 41 \%$ e $33 \%$ das vendas da categoria de lava-roupas nestes países, respectivamente $(\mathrm{H} \& \mathrm{C}, 2009)$. Estes números indicam que os lava- 


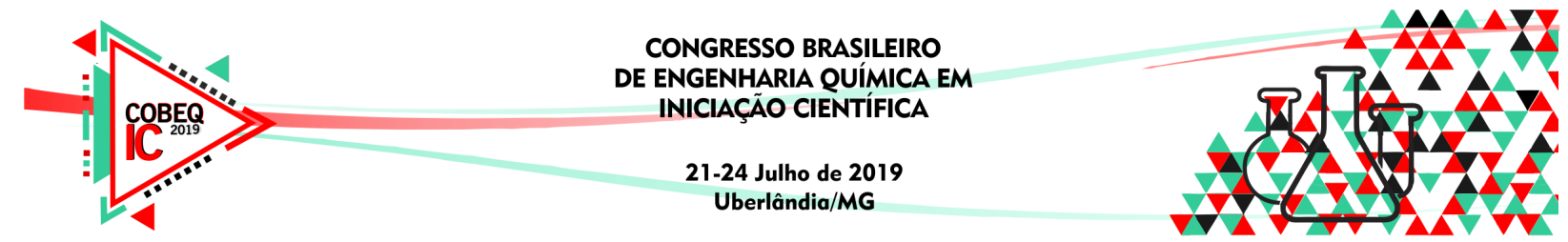

roupas líquidos são o futuro da categoria de produtos para cuidado com as roupas. O produto na forma líquida traz uma série de benefícios, oferece pré-tratamento de manchas difíceis, dissolve instantaneamente na água, penetra melhor nas fibras, e não deixa resíduos $(\mathrm{H} \& \mathrm{C}$, 2009). Além disso, a fabricação de detergente em pó exige estrutura complexa e difícil de financiar, o que dificulta o acesso de empresas de menor porte (ABRAS, 2015).

Seguindo o modelo dos demais países citados, há uma tendência no Brasil, nos próximos anos, da extinção da produção de detergentes na forma em pó, e de sua substituição por detergentes na forma líquida para a lavagem de roupas (H\&C, 2017).

Neste contexto, o presente trabalho teve como objetivo estudar a biodegradabilidade de tensoativo aniônico presente em uma amostra comercial de detergente lava-roupas líquido fabricado na região metropolitana de Belo Horizonte.

\section{MATERIAIS E MÉTODOS}

\subsection{Materiais}

O detergente lava-roupas líquido foi adquirido em um mercado local da região metropolitana de Belo Horizonte. Para solução padrão do tensoativo aniônico (linear alquilbenzeno sulfonato de sódio: LAS) foi utilizado dodecilbenzeno sulfonato de sódio (Neon) pureza $50 \% \mathrm{~m} / \mathrm{m}$. O inóculo de microrganismos foi obtido a partir de solo coletado no jardim do CEFET/MG. Os demais reagentes foram todos adquiridos em grau analítico.

\subsection{Métodos}

Determinação do teor de tensoativo aniônico no produto comercial: Dissolveu-se $25 \mathrm{~g}$ do detergente lava-roupas líquido em $100 \mathrm{~mL}$ de água destilada. Em seguida, neutralizou-se o sistema com NaOH (1 M) (utilizou-se solução de fenolftaleína como indicador). Posteriormente, transferiu-se a solução neutralizada para um balão volumétrico de $1000 \mathrm{~mL}$ e completou-se o volume com água destilada. Retirou-se $10 \mathrm{~mL}$ da solução preparada, transferiu-se para proveta de $100 \mathrm{~mL}$ com tampa e adicionou-se $30 \mathrm{~mL}$ de água destilada, $25 \mathrm{~mL}$ de solução de azul de metileno $\left(0,03 \mathrm{~g} \cdot \mathrm{L}^{-1}\right)$ e $15 \mathrm{~mL}$ de clorofórmio. Por fim, titulou-se a mistura com solução padrão de cloreto de benzalcônio $\left(0,004\right.$ mol. $\left.\mathrm{L}^{-1}\right)$, agitando o sistema a cada adição, até que ambas as fases apresentassem a mesma cor.

Preparo e leitura dos padrões: Em 8 funis de separação de $250 \mathrm{~mL}$ adicionou-se 1, 2, 5, 7, 12, 15 e $20 \mathrm{~mL}$ de solução padrão de LAS 0,01 g.L $\mathrm{L}^{-1}$ e água destilada para completar o volume de $100 \mathrm{~mL}$. Em seguida, adicionou-se, em cada sistema, 1 gota de fenolftaleína e, para que a solução atingisse tom róseo, 1 gota de $\mathrm{NaOH}(1 \mathrm{M})$, descorando-a em seguida com 1 gota de $\mathrm{H}_{2} \mathrm{SO}_{4}(0,5 \mathrm{M})$. Posteriormente, adicionou-se ao sistema $10 \mathrm{~mL}$ de clorofórmio e 25 $\mathrm{mL}$ de solução de azul de metileno $\left(0,03 \mathrm{~g} . \mathrm{L}^{-1}\right)$, agitou-se vigorosamente por 30 segundos e coletou-se a fase orgânica. Adicionou-se, $50 \mathrm{~mL}$ de solução de lavagem às fases orgânicas resultantes da extração e agitou-se vigorosamente por 30 segundos. Por fim, coletou-se as fases orgânicas em balões volumétricos de $50 \mathrm{~mL}$, completou-se o volume com clorofórmio e 


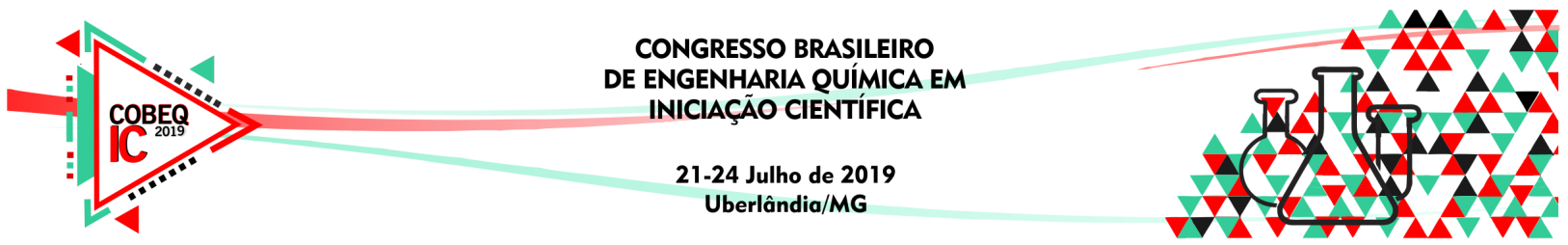

determinou-se a absorbância das amostras, em espectrofotômetro (UV/VIS - Mapada, modelo V-1100D) a $652 \mathrm{~nm}$, utilizando clorofórmio como branco.

Extração dos agentes tensoativos presentes no produto comercial: Mediu-se $20 \mathrm{~g}$ do detergente lava roupas líquido em erlenmeyer de $250 \mathrm{~mL}$, adicionou-se ao produto comercial $8 \mathrm{~g}$ de carbonato de potássio e $30 \mathrm{~mL}$ de isopropanol e agitou-se o sistema por 30 minutos em shaker. Em seguida, filtrou-se a mistura em funil de Buchner, lavou-se o resíduo com isopropanol, transferiram-se as duas fases para um funil de separação e recolheu-se a fase do isopropanol em um béquer. Extraiu-se então a fase aquosa com mais $10 \mathrm{~mL}$ de isopropanol, agitando-se por 1 minuto. Por fim, filtraram-se os extratos alcoólicos em cadinho filtrante com placa porosa de $\mathrm{n}^{\circ} 4$ e evaporou-se, o excesso de solvente, em chapa aquecedora, em um béquer de $500 \mathrm{~mL}$, a temperatura de $100{ }^{\circ} \mathrm{C}$ por $1 \mathrm{~h}$, sem secar completamente.

Preparo do inóculo: Mediu-se 25 g de solo de jardim, suspendeu-se em $250 \mathrm{~mL}$ de água destilada em erlenmeyer e manteve-se o sistema em repouso por 30 minutos. Em seguida, utilizando papel de filtro grosso, filtrou-se o sobrenadante, desprezando-se os primeiros $50 \mathrm{~mL}$.

Preparo do meio mineral: Dissolveu-se $0,3342 \mathrm{~g}$ de fosfato monobásico e $0,0175 \mathrm{~g}$ cloreto de amônio em $10 \mathrm{~mL}$ de água destilada e repetiu-se o procedimento com $0,2255 \mathrm{~g}$ de sulfato de magnésio, 0,2773 g de cloreto de cálcio e 0,0034 g de cloreto férrico (dissolveu-se separadamente cada um deles). Em seguida, transferiu-se $1 \mathrm{~mL}$ de cada uma das soluções preparadas para um béquer contendo $1000 \mathrm{~mL}$ de água destilada. Distribuiu-se então, em porções de $160 \mathrm{~mL}$, o meio mineral em 6 erlenmeyers de $250 \mathrm{~mL}$ e autoclavou-se os meios.

Ensaio de biodegradabilidade: Para cada $160 \mathrm{~mL}$ do meio mineral, colocado em erlenmeyer de $250 \mathrm{~mL}$, adicionou-se de 0,25 a $1 \mathrm{~mL}$ da solução estoque contendo LAS (1 g. $\mathrm{L}^{-1}$ ), ou das amostras em análise, buscando a obtenção de uma concentração final no meio em torno de $5 \mathrm{mg} \cdot \mathrm{L}^{-1}$. Nesse mesmo erlenmeyer, adicionou-se $0,75 \mathrm{~mL} \cdot \mathrm{L}^{-1}$ de inóculo. Foram retiradas alíquotas de $10 \mathrm{~mL}$ para determinação da concentração inicial das amostras e da solução padrão.

Os erlenmeyers contendo o meio mineral e a solução de referência foram colocados em shaker (ICELL, model 113) sob agitação, ao abrigo da luz, a temperatura ambiente (sem controle de temperatura). Retiraram-se alíquotas em dias pré-determinados, iniciando em volume de $10 \mathrm{~mL}$ e aumentando o volume das alíquotas à medida que a biodegradação se processava para obtenção de um resultado mais preciso. Esse procedimento foi realizado tanto para as amostras como para o padrão de LAS. A concentração de LAS a cada tempo foi determinada a partir da curva de calibração.

\section{RESULTADOS E DISCUSSÃO}

A Tabela 1 mostra o teor de matéria ativa aniônica presente na amostra de detergente líquido lava-roupas comercial estudado, bem como, o teor de tensoativo extraído desta amostra. 


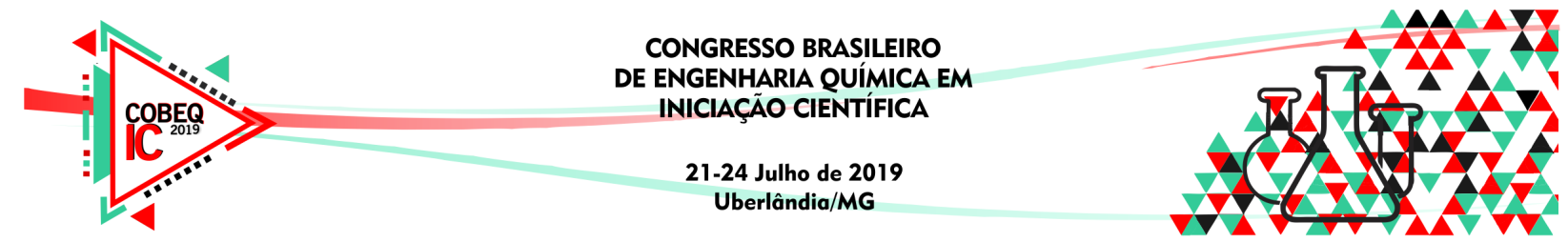

Tabela 1 - Teor de matéria ativa aniônica presente na amostra comercial de detergente líquido lava-roupas e teor de matéria aniônica extraída deste detergente

\begin{tabular}{|c|c|c|}
\hline Amostra & $\begin{array}{c}\text { Teor de matéria ativa aniônica } \\
(\%)\end{array}$ & $\begin{array}{c}\text { Teor de tensoativo extraído } \\
(\%)\end{array}$ \\
\hline $\begin{array}{c}\text { Detergente } \\
\text { lava-roupas líquido }\end{array}$ & 14,25 & 96 \\
\hline
\end{tabular}

Observa-se que o teor de matéria ativa aniônica $(14,25 \%)$ presente na amostra de detergente lava-roupas estudada está dentro do limite mínimo especificado pela legislação brasileira para detergente líquido para limpeza de artigos de copa e cozinha concentrado (ANVISA, 1978), tendo em vista que, esta estabelece que o produto deve conter no mínimo $10 \%$ em matéria ativa aniônica. Este resultado está em acordo com Osadebe e colaboradores (2018) que afirma que em detergentes comerciais o conteúdo de surfactantes em geral está entre 10 a $20 \%$. O resultado se aproxima também do valor mínimo da faixa (15 a $20 \%$ ) apresentada por Landeck e outros pesquisadores (2018) para detergentes lava-roupas líquidos destinados a limpeza pesada na Europa. Não foi encontrado na legislação brasileira um limite específico para detergente líquido lava-roupas, provavelmente porque a tendência de crescimento deste seguimento ainda é recente no Brasil.

É importante ressaltar que a amostra estudada representa uma marca local (fabricada na região metropolitana de Belo Horizonte) sendo, portanto, pouco conhecida, e mesmo assim apresentou concentração elevada. É provável que se trate de um produto concentrado, o que é uma tendência atual dos produtos de limpeza (H\&C, 2018), tendo em vista além de questões ambientais (economia de água e embalagens), as mudanças de estilo de vida do consumidor, devido à crise econômica, que conduziu a busca por produtos que oferecem mais facilidade de uso e resultados superiores. Acredita-se que, apesar do detergente lava roupas-líquido de marca não conhecida no mercado brasileiro apresentar um valor de venda reduzido em comparação a outros produtos reconhecidos nacionalmente, este fator não determina que a matéria-prima utilizada para sua formulação esteja presente em menor quantidade, já que o custo de um produto depende, entre outros fatores do seu marketing relacionado a sua marca.

Com relação ao teor de tensoativo extraído da amostra estudada o resultado encontrado foi de $96 \%$, ficando, portanto, dentro do limite previsto pela legislação (ANVISA, 1998), que determina um mínimo de $90 \%$.

A Figura 1 apresenta os resultados de biodegradabilidade do tensoativo extraído da amostra de detergente líquido lava roupas comercial, comparativamente ao padrão de LAS.

É possível constatar que a amostra de detergente lava-roupas líquido analisada atingiu uma porcentagem de biodegradação superior a $90 \%$ no $9^{\circ}$ dia de teste, podendo ser, portanto, considerada biodegradável segundo a legislação brasileira (ANVISA, 1998), que determina um mínimo de $90 \%$ até o $14^{\circ}$ dia de ensaio.

Este resultado se aproxima ao obtido por Ribeiro e colaboradores (2018) na análise de detergente lava-roupas em pó que, já em torno do $7^{\circ}$ dia, a amostra apresentou aproximadamente $90 \%$ de degradação. 


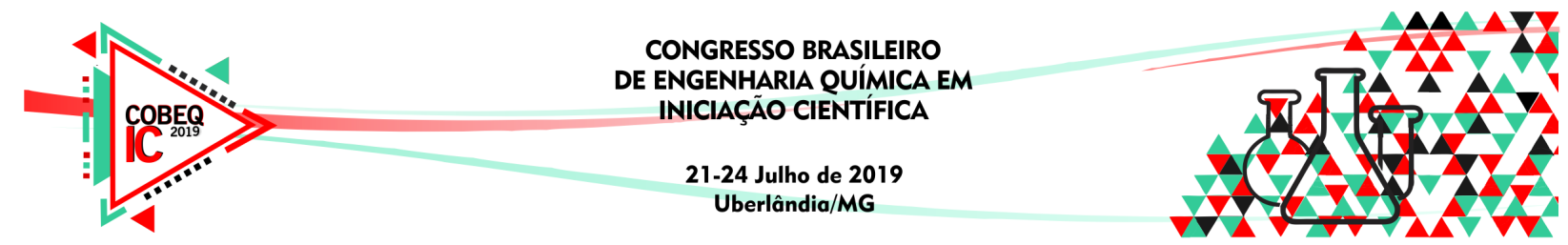

Figura 1 - Curva de biodegradabilidade: Comparação entre padrão de LAS e amostra extraída de detergente lava-roupas líquido fabricado na região metropolitana de Belo Horizonte.

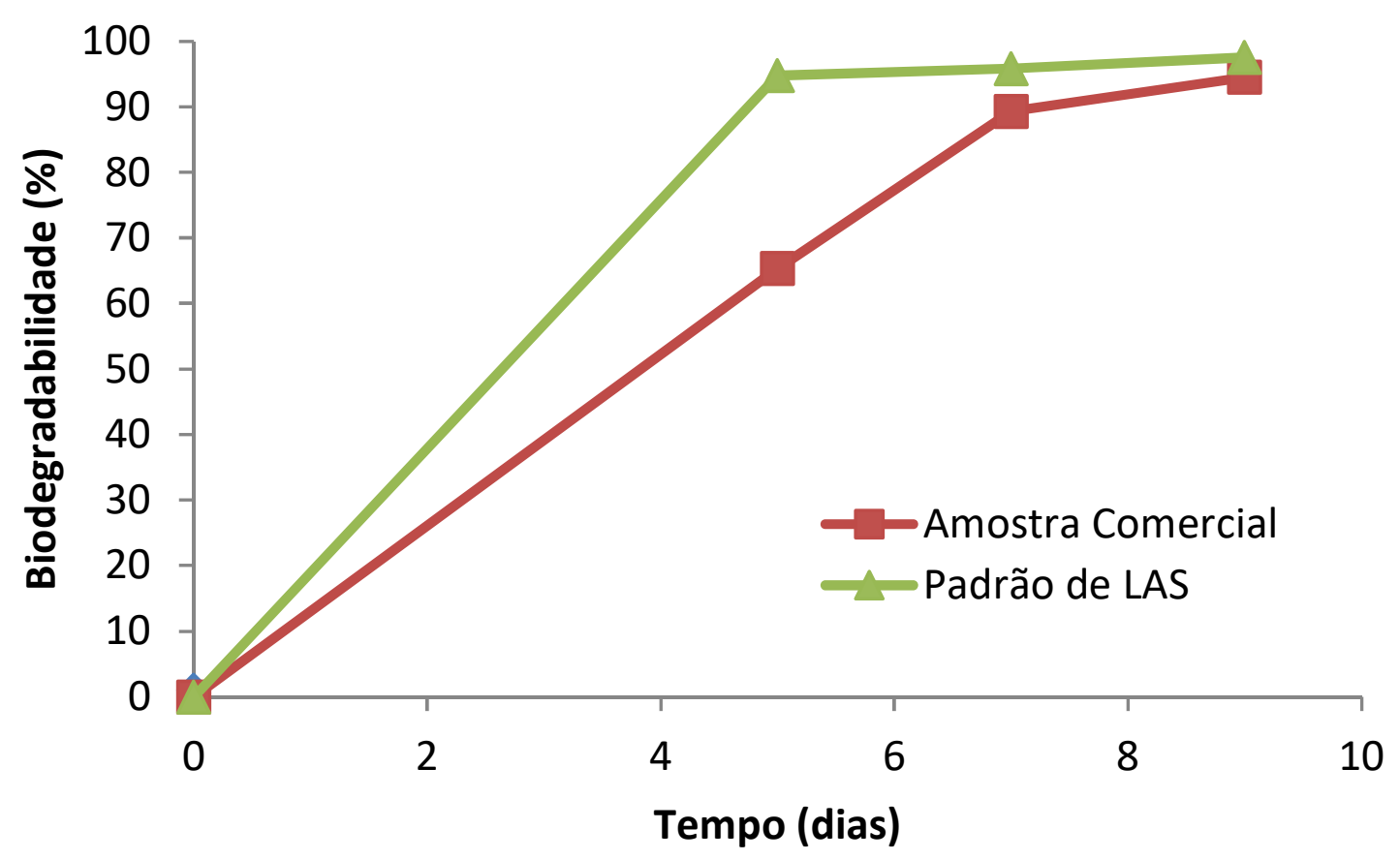

\section{CONCLUSÃO}

A análise da amostra estudada mostrou que, além do detergente de marca regional apresentar teor de ativo dentro do indicado para legislação brasileira para um detergente da categoria concentrado, o mesmo é biodegradável, já que sua taxa de biodegradação foi superior a $90 \%$ no $9^{\circ}$ dia de ensaio, ou seja, antes do que preconiza a legislação brasileira (até 14 dias). Acredita-se que, apesar do detergente lava roupas-líquido de marca não evidenciada no mercado nacional apresentar um preço de venda menor, comparativamente a produtos de marcas líderes no mercado brasileiro, este fator não determina que a matériaprima utilizada para sua formulação esteja em menor quantidade ou seja de qualidade inferior, tendo em vista que, o valor de um produto está sujeito, além do custo de matérias-primas, a muitos outros fatores, dentre os quais destaca-se o marketing envolvido com sua marca.

\section{NOMENCLATURA}

ANVISA - Agência Nacional de Vigilância Sanitária

CEFET/MG - Centro Federal de Educação Tecnológica de Minas Gerais

LAS - Linear alquilbenzeno sulfonato de sódio 


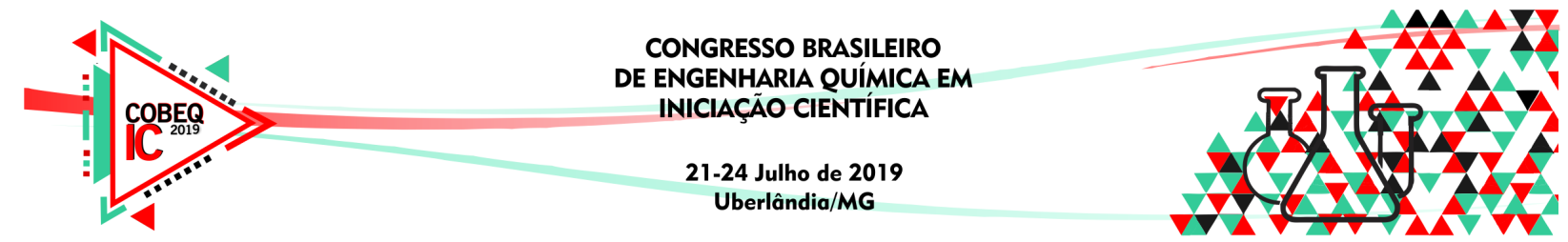

\section{REFERÊNCIAS}

ANVISA, Portaria n³93, e 15 de maio de 1998 da Secretaria de Vigilância Sanitária. Art. $1^{\circ}$ - Estabelecimento do método de determinação da biodegradabilidade de tensoativos aniônicos, com validade em todo território Nacional, 1998.

ANVISA, Resolução Normativa ${ }^{\circ} 1$, de 27 de novembro de 1978 da Secretaria de Vigilância Sanitária. Normas sobre detergentes e seus congêneres com validade em todo território Nacional, 1978.

ABRAS, Fabricantes de produtos para lavar roupa esperam alta das vendas no ano. Associação Brasileira de Supermercados, 2015. Disponível em: http://www.abras.com.br.

BNDES (Banco Nacional de Desenvolvimento Econômico e Social). Potencial diversificação da indústria química Brasileira, Relatório 4: Tensoativos. Chamada Pública BNDES/FEP $n^{\circ} 3 / 2011$, Rio de Janeiro, novembro de 2014. Disponível em: http://www.bndes.gov.br.

GONÇALVES, C.M.R. Estudo da biodegrabilidade de um efluente industrial. Dissertação de Mestrado em Engenharia do Ambiente e Tecnologias Ambientais. Instituto Superior de Agronomia, Universidade Técnica de Lisboa. Lisboa, 2009.

H\&C. Fabricantes prometem mercado ainda mais forte. Household \& Cosméticos n. 102, junho 2017.

H\&C. Mais tecnologia, menos esfrega-esfrega. Household \& Cosméticos. n. 58, novembro / dezembro, 2009.

H\&C. Premiunização impulsiona vendas dos detergentes concentrados. Household \& Cosméticos. Maio/Junho, 2018.

LANDECK, L.; Baden, L. A.; John, S.-M. Detergents. Kanerva's Occupational Dermatology. p. 1-15, 2018.

OSADEBE, A.U.; ONYILIOGWU, C.A.; SULEIMAN, B.M.; OKPOKWASILI, G.C. Microbial Degradation of Anionic Surfactants from Laundry Detergents Commonly Discharged into a Riverine Ecosystem. J. Appl. Life Sci. Int. v.16, n. 4, p. 1-11, 2018.

RIBEIRO, B.C.J.; VIEIRA, M.L.A.; NUNES, G.F.M. Estudo das condições de extração de tensoativo aniônico contido em detergente lava roupas em pó para o acompanhamento de sua biodegradação. I Simpósio de Engenharia Urbana, PUC Minas Barreiro, Belo Horizonte/MG, 29 a 31 de outubro de 2018.

\section{AGRADECIMENTOS}

Os autores agradecem a FAPEMIG, e ao CEFET/MG pelo apoio concedido para o desenvolvimento e apresentação deste trabalho. 